\title{
Metodologia para estruturação de cadeias de suprimentos no agronegócio: um estudo exploratório
}

\author{
$\overline{\text { Egidio L. Furlanetto }^{1} \text { \& Gesinaldo A. Cândido }}{ }^{2}$
}

\begin{abstract}
RESUMO
O sucesso do agronegócio está fortemente ligado ao grau de articulação de seus diferentes elos e, conseqüentemente, da eficiência de seus mecanismos de coordenação em responderem às imposições do mercado, sendo fundamental que suas cadeias sejam estruturadas e coordenadas sob esta ótica. Objetivando contribuir com o tema, o presente trabalho apresenta uma metodologia voltada à estruturação de cadeias de suprimentos do agronegócio, a qual é fruto de três estudos de caso, realizados em diferentes formas de estruturação e coordenação dos sistemas de produção do agronegócio: uma cooperativa agrícola, uma integradora de frangos e a cadeia de suprimentos de carne bovina de uma rede de supermercados. Procurou-se, neste estudo, analisar o processo de estruturação das cadeias, ou seja, como foram estruturadas, como estão sendo coordenadas e quais suas principais características e, a partir dos resultados dos três casos, foram definidas, via de regra, as principais etapas do processo de estruturação de uma cadeia de suprimentos do agronegócio.
\end{abstract}

Palavras-chave: cadeia produtiva, gestão, suprimentos

\section{Methodology for structuring agribusiness supply chain: An exploratory study}

\begin{abstract}
The success of the agribusiness is strongly associated with the degree of articulation of its different links and the result of the efficiency of its coordination mechanisms in answering the impositions of the market; it is fundamental that agribusiness chains are structured and coordinated keeping these aspects in view. The present work presents a methodology for structuring agribusiness supplies chains. The methodology is a result of three Case Studies conducted in different structured forms and coordination of the production systems of the agribusiness: an agricultural cooperative, an integrator of chickens and the supply chain of bovine meat from a net of supermarkets. The study intended to analyze the process of structuring these chains; in other words, how these are structured, coordinated and their main characteristics. From the results of the three cases, the main stages of the process of structuring a supply chain of the agribusiness were defined.
\end{abstract}

Key words: productive chain, management, supply, coordination 


\section{INTRODUÇÃO}

Compreendido por uma cadeia de operações que envolvem desde a fabricação de insumos, a produção nas fazendas, a transformação (industrialização), distribuição e comercialização, chegando ao consumidor final, o agronegócio brasileiro é responsável por cerca de $40 \%$ dos valores exportados pelo comércio exterior, constituindo-se numa das principais fontes de divisas para o País.

Este sucesso do agronegócio brasileiro e, de forma geral, do agronegócio mundial, se vincula, em parte, ao grau de articulação de seus diferentes elos e, conseqüentemente, da eficiência de seus mecanismos de coordenação em responderem às imposições do mercado.

Dentro desta lógica, a empresa rural constitui apenas mais um elemento importante; entretanto, integrado numa rede de vinculações a outros sistemas: comercial, financeiro, infraestrutura, tecnologia, relações do trabalho e todo o aparato institucional público e privado, configurando o que se convencionou chamar de cadeia produtiva.

Portanto, uma análise do conceito de cadeia produtiva permite a identificação de interações existentes entre os diversos elos que a compõem. Essas interações estabelecem relações de complementaridade e de interdependência entre os atores envolvidos numa lógica seqüencial e dinâmica.

Assim, tanto as instituições como as organizações perceberam que a eficiência do moderno agronegócio passou a apoiar-se cada vez mais nos aspectos estruturais da cadeia produtiva, na medida em que depende da capacidade de resposta à evolução da demanda veiculada pela grande distribuição e exige novas formas de integração a montante, para assegurar os fluxos e a qualidade da matéria-prima.

Vislumbra-se, portanto, um novo enfoque, com a competição ocorrendo muito mais entre cadeias, onde não é mais possível planejar setorialmente, sem se levar em consideração os desdobramentos ao longo da cadeia produtiva, em especial no caso do Agronegócio, altamente dependente das mais diversas exigências de mercado e legais (ambiental e de saúde).

Este novo enfoque (paradigma) pressupõe que se trate da competitividade sistêmica, sendo fundamental que se busquem mecanismos para a formação de cadeias de valor, incorporando conhecimentos em todas as formas de interação entre os componentes da cadeia. Desta forma, a cadeia precisa de mecanismos através dos quais se busque conhecer e mapear, sistematicamente: 1) tendências para diferenciação de produtos, com estratégias explícitas; 2) controles institucionais e 3) controle dos variados fornecedores, ou seja, torna-se fundamental a criação das melhores condições para otimizar a governança da cadeia como um todo e, em especial, no caso do agronegócio, das cadeias de suprimentos.

A partir de então, diferentes pesquisadores se têm envolvido em projetos que objetivam a construção de caminhos que possibilitem melhor integração entre os diferentes elos que compõem uma cadeia produtiva (Davis \& Goldberg, 1957; Goldberg, 1968; Lauret, 1978; Zylbersztajn, 1995; Zylbersztajn, 2000).

Para esses pesquisadores, sobretudo para os que tratam do agronegócio, uma das questões centrais tem sido: Como estruturar as cadeias produtivas do agronegócio para que as empresas nele inseridas façam frente aos novos desafios a elas impostos pela nova realidade do mundo dos negócios?

Neste caso e pela própria gênese da cadeia, constituída por diferentes e independentes elos, é ressaltada a necessidade de coordenação desses elos que a configuram, os quais apresentam interesses e ações muitas vezes conflitantes (Pfeffer \& Salancik, 1978). Portanto, passou a ser fundamental tratar da estruturação e coordenação das cadeias e, por conseguinte, da necessidade de gestão da cadeia como um todo (Ching, 1999), o que pode proporcionar o aumento da produtividade e contribuir significativamente para a redução de custos (Williamson, 1989) e identificar formas de agregar valor aos produtos e serviços.

Objetivando contribuir na solução desta questão apresenta-se, no trabalho, uma metodologia para estruturação de cadeias produtivas do agronegócio, adotando-se a cadeia de suprimentos como objeto de análise, e isto se deu em função de ser este um conceito de melhor operacionalização. Tal metodologia é fruto de três estudos de caso, realizados em três diferentes formas de estruturação e coordenação dos sistemas de produção do agronegócio, quando então se procurou analisar o processo de estruturação dessas cadeias, isto é, como foram estruturadas, como estão sendo coordenadas e quais suas principais características.

Portanto, o objetivo da pesquisa consistiu em identificar o processo de estruturação das cadeias de suprimentos e, a partir daí, definir uma metodologia de estruturação das cadeias de suprimentos do agronegócio.

Para se alcançar os propósitos, dividiu-se este artigo no sentido de apresentar, além desta introdução, a metodologia de pesquisa; a análise dos casos; os resultados da pesquisa e as considerações finais.

\section{MATERIAL E MÉTODOS}

Para a consecução dos objetivos propostos no trabalho utilizou-se a técnica de múltiplos estudos de caso. As organizações estudadas foram escolhidas sob critérios de eficiência e representatividade, isto é, procurou-se selecionar cadeias eficientes e representativas, do Estado do Rio Grande do Sul, área delimitada para o estudo. Para identificar os sistemas produtivos mais eficientes, foram consultados especialistas ligados a cada uma delas.

Por questões de operacionalização, o objeto de estudo concentrou-se na cadeia de suprimentos, aqui considerada um corte na cadeia produtiva, ou seja, uma rede de sistemas de produção e distribuição, que transforma a matériaprima em produtos intermediários ou acabados e os distribui aos consumidores (Ching, 1999). Tal delimitação conceitual permitiu, portanto, que fossem analisadas as cadeias de suprimentos de três diferentes empresas, com todas as suas ramificações, as quais são inerentes a qualquer cadeia (produtiva ou de suprimentos).

Procurou-se analisar o processo de formação e estruturação das diferentes cadeias, especialmente como estas são 
coordenadas, visto ser este o principal pressuposto assumido ao longo do trabalho, ou seja, que a competitividade do agronegócio está associada à necessidade de uma estrutura de coordenação que articule os diferentes elos.

$\mathrm{O}$ instrumento de coleta dos dados - roteiro das entrevistas - foi elaborado com auxílio do referencial teórico apresentado e no sentido de se obterem subsídios para responder como cada sistema se organizou e como está sendo coordenado.

Após definição dos sistemas a serem pesquisados e com auxílio do roteiro de entrevistas, foram entrevistados os dirigentes das empresas líderes das cadeias. A partir dessas entrevistas, foram desenhadas as cadeias de suprimentos de cada uma das empresas, permitindo-se a identificação dos principais segmentos que as constituem e posterior entrevista de seus representantes.

A definição do dirigente a ser entrevistado obedeceu ao seguinte critério: nos casos em que a empresa possuía o gerente de suprimentos, este foi o elemento indicado; nos outros casos, a preferência recaiu sobre um executivo do alto escalão da empresa (gerente, diretor, diretor presidente). Procurou-se realizar entrevistas com mais de um dirigente das empresas analisadas e de seus fornecedores os produtores.

\section{Análise dos casos}

Estudo de caso $\mathbf{n}^{0}$ 1. Cadeia de suprimentos de Frangos da Avipal S/A - Agricultura e Agropecuária de Porto Alegre, RS

A Avipal é considerada uma das maiores e mais eficientes empresas do setor de alimentos do estado do Rio Grande do Sul, operando principalmente com aves, suínos, leite e todos os seus derivados. Objetivou-se, com o estudo deste caso, analisar a estrutura organizacional em que pequenos e médios produtores operam de forma integrada a uma empresa do agronegócio. O sistema de integração de aves foi escolhido por se tratar de um dos mais consolidados e competitivos. Foram entrevistados o gerente de fomento e o diretor adjunto da Avipal, além de dois produtores de frangos que trabalham integrados à empresa.

A dinâmica da cadeia pode ser assim resumida: a Avipal traça toda a estratégia, realiza o planejamento, seleciona os produtores e dá partida a todo o processo produtivo, isto é, planeja a produção, efetua toda a parte de compras, pesquisa, produz rações, incuba os ovos, repassando, então, somente a operação de engorda das aves aos produtores integrados. $\mathrm{Na}$ época adequada recolhe as aves adultas, processa o abate e as comercializa. Aos produtores cabe somente a tarefa de criação (engorda) das aves.

Estudo de caso $\mathbf{n}^{0}$ 2. Cadeia de suprimento de carne bovina da Companhia Zaffari de Supermercados, Porto Alegre, RS

A Companhia Zaffari de Supermercados é uma rede composta por dezenove lojas (janeiro/2001), dezessete delas em Porto Alegre e duas no interior do Estado constituindo-se, na época do estudo, na segunda maior rede de supermercados do Rio Grande do Sul e a sétima no Brasil.

O objeto de análise foi sua cadeia de suprimentos de carnes, composta por doze frigoríficos e um grande número de produtores, todos localizados no Estado do Rio Grande do Sul. A razão da escolha ocorreu devido ao fato da rede ser uma das mais eficientes do Estado e desenvolver um sistema de parceria ao longo da cadeia, o qual envolve frigoríficos e criadores de gado; além disso, a quase totalidade da carne é comercializada com marca própria - o Novilho Jovem Zaffari, fruto dessas parcerias.

Foram entrevistados o encarregado pelo setor de carnes da rede de supermercados, o médico veterinário, que participa desde o início do projeto e é, atualmente, consultor do programa, atuando como credenciador e inspetor dos fornecedores de carne, bem como o executivo responsável pelo setor comercial do frigorífico Extremo Sul de Pelotas, um dos fornecedores da rede de supermercados.

A dinâmica da cadeia é a seguinte: a rede Zaffari, com base nas suas previsões de venda, faz os pedidos aos frigoríficos que despacham a carne, na maioria das vezes diretamente para as lojas da rede. Toda a carne chega às lojas desossada, em cortes definidos (padronizados) e embalada. A rede dispõe, também, de uma câmara fria para manter um estoque estratégico; entretanto, é de interesse da empresa que toda a carne seja remetida diretamente às lojas. Quanto aos produtores, eles recebem todo o apoio dos frigoríficos, com os quais alguns possuem parcerias.

Estudo de caso $\mathbf{n}^{\mathbf{0}}$ 3. Cadeia de suprimentos de grãos da Cooperativa Tritícula Mista Alto Jacuí, Não-me-Toque, RS - COTRIJAL

A COTRIJAL, é uma cooperativa agrícola cuja produção de grãos é sua principal atividade, possui 700 funcionários e conta com 3.500 associados. De acordo com especialistas ligados à OCRS (Organização das Cooperativas do Rio Grande do Sul) e consultados na escolha do caso, a COTRIJAL é considerada uma das mais eficientes cooperativas agrícolas do Estado do Rio Grande do Sul atuando, também, na produção animal, destacando-se a suinocultura e o gado leiteiro.

A COTRIJAL conta com dez entrepostos, distribuídos ao longo de sua área de atuação, abrangendo dez municípios da região norte do Estado do Rio Grande do Sul. Em 1990, a partir do momento em que a cooperativa começou a discutir a melhor forma de organização de seus produtores, ela iniciou, também, a modificação de seu modo de gestão, alterando a sua forma de contabilização e gerenciamento. A partir daí, mudou o seu plano de contabilização e, em discussão com o Conselho e a Assembléia, foi dividida em Unidades Estratégicas de Negócios. Hoje, é formada por três grandes Unidades de Negócios: a unidade de grãos, a de produção animal e a de varejo e consumo, todas responsáveis pela geração de resultados.

Neste estudo de caso foram entrevistados o gerente da Unidade de Grãos da COTRIJAL, dois produtores associados à cooperativa e, com o objetivo de aprofundar o entendimento das relações entre a cooperativa e o seu associado, foi também entrevistado o assessor de comunicação e educação da cooperativa.

A cadeia objeto de estudo se compõe por toda a estrutura de apoio da Cooperativa, iniciando na pesquisa, assistência técnica, comercialização de insumos, chegando à armazenagem e comercialização dos grãos e passando pelos 
produtores. Em suma, o objeto de análise constitui-se de uma grande estrutura composta por 3.500 propriedades rurais e uma organização que integra e coordena todas as atividades, configurando-se em uma empresa de grandes dimensões, com estabelecimentos em diferentes locais.

\section{RESULTADOS E DISCUSSÃO}

Não obstante o fato de assumirem formas diferentes, em todos os três casos pesquisados predomina estruturas de coordenação com objetivos e funções semelhantes. As três cadeias foram estruturadas a partir de relações qualificadas entre os agentes, o que implica formas alternativas de coordenação, diferentes do mercado e da hierarquia. Tratam-se, na verdade, de estruturas de coordenação híbridas, isto é, intermediárias entre mercado e hierarquia, as quais passam a agir no sentido de otimizar as transações de modo sistêmico: é o todo estabelecido no sentido de proporcionar competitividade ao sistema.

Nos casos da Avipal e da COTRIJAL, as semelhanças são grandes, com as duas empresas procurando coordenar boa parte de uma cadeia produtiva, a primeira de frangos e a segunda de grãos. A Avipal procura coordenar todas as transações, desde a importação das “avós” até a comercialização dos frangos, fornecendo toda a ração para alimentar as aves, bem como os medicamentos, as vacinas necessárias e toda a informação técnica relativa ao seu tratamento e manejo. Quanto ao preço, é a integradora que decide o que será pago ao produtor, tomando por base somente a sua planilha de custos, embora o preço final seja definido pelo mercado. O mesmo ocorre na COTRIJAL, com a cooperativa coordenando tanto os elos iniciais da cadeia (fornecimento de sementes, insumos, assistência técnica, etc.), como as etapas da produção, assistência técnica, armazenagem e comercialização dos produtos.

Assim sendo, com base nos três casos é possível definir algumas das principais etapas necessárias para a construção e definição dessas estruturas, ou seja:

\section{Identificação dos agentes}

Em todas as cadeias analisadas, a identificação dos agentes constituiu um dos primeiros passos para a estruturação das cadeias.

No caso da Companhia Zaffari, é a rede que assume a responsabilidade na identificação, qualificação e monitoramento dos frigoríficos, repassando-lhes todas as informações, para que eles façam o mesmo em relação aos produtores. Este processo de identificação é fundamental, também, nos casos da Cooperativa e da integradora de frangos, já que possibilita que os produtores recebam toda assistência técnica junto às suas propriedades, pois tanto a Cooperativa como a integradora mantêm equipes em constante visita aos produtores.

Portanto, ao longo de todas as cadeias estudadas as transações ocorrem entre agentes identificados e acompanhados, isto é, elas podem ser classificadas como qualificadas e entre agentes que transacionam com base no seu histórico, construído na relação.

\section{A presença de ações conjuntas - cooperação}

A cooperação é vista, pelas empresas, como forma de reduzir riscos e custos. Para o gerente de fomento da Avipal, a empresa considera o produtor seu parceiro e procura agir desta maneira. No caso Zaffari, a estrutura montada se sustenta na cooperação entre os três principais elos - a rede de supermercado, os frigoríficos e os produtores. Conforme o especialista e consultor do programa, "um depende do outro e todos da força do conjunto” e foram essenciais, principalmente no início do processo, pois acabaram alterando o ambiente, contribuindo para a criação de um novo paradigma, o do aproveitamento da carne de animais mais jovens. O mesmo ocorre com a COTRIJAL, ao estabelecer parcerias, tanto para trás como para frente.

\section{Flexibilização de contratos}

Nas diferentes cadeias estudadas predominam contratos que podem ser denominados "informais" e ocorrem em clima de confiança, entre parceiros identificados, que possuem o expresso desejo de permanecer na relação, sendo as “falhas contratuais”, preferencialmente, resolvidas entre as partes. Quanto à sua tipologia, assemelham-se muito mais aos caracterizados por Macneil (1978) apud Williamson (1989) como contratos relacionais, havendo grande flexibilidade e visão de longo prazo.

\section{Livre fluxo de informações}

As empresas reconhecem a importância da informação no processo e procuram criar condições para que haja o seu fluxo entre os agentes que compõem suas cadeias de suprimentos.

No caso da Avipal, o fluxo de informações é constante, iniciando-se quando o produtor faz o primeiro contato com a empresa e recebe a visita da assistência técnica. Para a rede de supermercados Zaffari, é fundamental que tanto o frigorífico como o produtor tenham conhecimento das vantagens de explorar a precocidade dos animais e de ofertar um produto de procedência. Neste sentido, dispõe de canais de informações com seus fornecedores, procurando munir de informações toda a cadeia, repassando o conhecimento acumulado e as informações oriundas do mercado; já no caso da COTRIJAL, as informações ocorrem sob um fluxo contínuo, nos dois sentidos, com o técnico levando informações ao produtor (as justificativas das ações da cooperativa) e, ao mesmo tempo, trazendo-as, juntamente com as suas solicitações.

\section{Padronização das ações}

Cada uma das cadeias procura funcionar sob a sua própria lógica, porém todas elas partem do princípio de que, ao padronizar as ações, conseguirão maior eficiência nos processos, já que são padronizados os procedimentos considerados os melhores (best practice).

A Avipal tem interesse expresso em padronizar as ações para obter maior produtividade, confiabilidade e permitir que o processo seja monitorado a qualquer momento. Por se tratar de um produto (frango) sujeito a doenças, que necessita de um rigoroso controle sanitário e de um rasteamento (monitoramento) constante é vital, para a empresa, que as ações 
e procedimentos sejam todos padronizados. No caso da rede Zaffari de Supermercados, a padronização foi um dos itens em que a rede, conjuntamente com os frigoríficos, precisou trabalhar mais, pois um dos diferenciais do produto era exatamente o padrão de cortes, que é internacional. O mesmo ocorre na COTRIJAL, com os procedimentos e ações de recebimento sendo iguais em todos os entrepostos da cooperativa. Em comum acordo com a direção da cooperativa, a equipe técnica e os produtores, o modelo de exploração da terra é definido e deve ser, preferencialmente, seguido por todos os associados, embora não seja tão rígido.

\section{Resolução dos conflitos}

As cadeias analisadas caracterizam-se pela apresentação de um ambiente de negócios com baixa incidência de conflitos e pela capacidade em gerenciá-los sem a interveniência externa de uma terceira parte.

Os conflitos são mais constantes nas estruturas mais abertas, como é o caso da cooperativa, cujos produtores/fornecedores são, também, seus proprietários. Ao comprar os insumos da cooperativa, o produtor quer fazê-lo pelos menores preços de mercado, ao passo que, ao vender sua produção, quer obter os maiores preços criando-se, assim, um conflito porém, como declarou o representante da cooperativa esses conflitos são administrados e solucionados via esclarecimento do associado. No caso dos criadores de frango integrados, principalmente pela cultura já existente na região, os conflitos são insignificantes e podem ser traduzidos por reivindicações que visam aumentar seus ganhos; já na rede de supermercados Zaffari são raros os conflitos e, quando ocorrem, referem-se, basicamente, à qualidade dos produtos.

\section{Construção de uma marca para a cadeia}

Em se tratando de cadeia de suprimentos e suas imbricações, pode-se pensar em procurar explorar um objetivo comum e uma marca que identifique a cadeia, como um todo. Muitas vezes, essa identificação de marca vem associada à imagem de determinada cadeia de um produto e vinculada a um local geográfico específico. O caso mais ilustrativo é o da cooperativa, em que várias cadeias procuram explorar as vantagens de uma única marca - a marca COTRIJAL. No caso da integração de frangos, a única marca explorada, tanto pelos produtores de frango como pela empresa, é a Avipal. Ao longo da cadeia existe uma identificação com a marca da empresa e todos estão engajados em trabalhar para ela e o mesmo ocorre com a cadeia de carnes da rede de supermercados.

\section{Compartilhamento dos lucros}

Indiretamente, todos os agentes que participam das cadeias analisadas acabam sendo beneficiados dos ganhos da empresa líder, pois mesmo não sendo beneficiados diretamente dos lucros das empresas líderes das cadeias, os seus fornecedores foram unânimes em afirmar ser de seu interesse que elas obtenham lucro, pois estarão assegurando mercado para seus produtos e divulgando o nome de suas empresas.

Em suma e com exceção da cooperativa, em que os lu- cros são repassados de forma direta e estão estabelecidos em lei, o que ocorre é que, de forma indireta, os benefícios da empresa líder acabam sendo repassados aos fornecedores/ parceiros.

A Tabela 1 apresenta uma síntese das principais etapas por que passam os mais diferentes agentes ao longo das cadeias de suprimentos, no seu processo de estruturação.

Tabela 1. Etapas importantes na estruturação das cadeias de suprimentos

\begin{tabular}{|c|c|}
\hline Etapas & Especificidades \\
\hline $\begin{array}{l}\text { 1. Identificação dos } \\
\text { agentes }\end{array}$ & $\begin{array}{l}\text { Transações entre agentes identificados e que } \\
\text { manifestam o desejo de continuar na relação são mais } \\
\text { confiáveis e menos susceptíveis ao oportunismo. }\end{array}$ \\
\hline $\begin{array}{l}\text { 2. Desenvolvimento de } \\
\text { parcerias }\end{array}$ & $\begin{array}{l}\text { As parcerias efetuadas ao longo dos diferentes elos } \\
\text { diminuem riscos e investimentos. }\end{array}$ \\
\hline $\begin{array}{l}\text { 3. Definição de contratos } \\
\text { flexíveis }\end{array}$ & $\begin{array}{l}\text { Contratos de longa duração, muitas vezes informais, } \\
\text { renegociáveis e flexíveis. }\end{array}$ \\
\hline $\begin{array}{l}\text { 4. Livre fluxo de } \\
\text { informações }\end{array}$ & $\begin{array}{l}\text { As informações predominantemente fluem nos dois } \\
\text { sentidos da cadeia, não se limitando somente a } \\
\text { quantidades e preços. }\end{array}$ \\
\hline 5. Padronização de ações & $\begin{array}{l}\text { Cada cadeia procura transacionar sob a sua lógica } \\
\text { e com padrões definidos. }\end{array}$ \\
\hline 6. Resolução dos conflitos & $\begin{array}{l}\text { Os conflitos são, predominantemente, resolvidos } \\
\text { entre as partes. }\end{array}$ \\
\hline $\begin{array}{l}\text { 7. Construção de uma } \\
\text { marca }\end{array}$ & $\begin{array}{l}\text { As transações dentro de uma mesma cadeia são } \\
\text { orientadas, prioritariamente, por um objetivo único. }\end{array}$ \\
\hline $\begin{array}{l}\text { 8. Compartilhamento dos } \\
\text { lucros }\end{array}$ & $\begin{array}{l}\text { Os benefícios advindos de esforços cooperados } \\
\text { acabam de forma direta ou indireta sendo } \\
\text { repassados aos membros de toda a cadeia. }\end{array}$ \\
\hline
\end{tabular}

\section{CONCLUSÕES}

1. Projetos que visam integrar e coordenar cadeias de suprimentos do agronegócio necessitam, dentro do possível e sempre resguardando suas particularidades, analisar, em maior ou menor intensidade, as contribuições aqui apresentadas.

2. É fundamental que as empresas que atuam no agronegócio planejem suas atividades visualizando a cadeia como um todo, procurando integrar-se tanto à jusante, como à montante.

3. É importante ressaltar que as alternativas de formas organizacionais não se esgotam nestes três casos e que novos estudos necessitam ser desenvolvidos no sentido de melhor orientar esta escolha.

\section{LITERATURA CITADA}

Ching, H. Y. Gestão de estoque na cadeia logística integrada: Supply chain. São Paulo: Atlas, 1999. 196p.

Davis, J. H.; Goldberg, R. A. A concept of agribusiness. Boston: Harvard University, 1957. 136p.

Goldberg, R. A. Agribusiness coordination: A Systems approach to the wheat, Spybean, and Florida orange economies. Boston: Harvard University, 1968. 256p. 
Lauret, F. Sur l'etudes de filières agro-alimentaires. Revue èconomies et societés, chaiers de L’ISMEA, Paris. Série AG, n.17, p.721-740, 1978.

Pfeffer, J.; Salancik, G. R. The external control of organizations: A resourse dependence perspective. New York: Harper and Row, 1978. 300p.

Williamson, E. Las instituciones económicas del capitalismo. Trad. Eduardo L. Suarez. México: Fondo de Cultura Económica, 1989. 435p.
Zylbersztajn, D. Estruturas de governança e coordenação do agribusiness: uma aplicação da nova economia das instituições. São Paulo: FEA/USP, 1995. 238p. Tese LivreDocência

Zylbersztajn, D. Conceitos gerais, evolução e apresentação do Sistema agroindustrial. In: Zylbersztajn, D.; Neves, M. F. (org.). Economia e gestão dos negócios agroalimentares. São Paulo: Pioneira, 2000. cap.1, p.1-23. 